\title{
Tobacco control policies and activities in Aboriginal community-controlled health services
}

\begin{abstract}
A boriginal communitycontrolled health services (ACCHSs) have long recognised tobacco use as an important contributor to poor health outcomes in their communities, ${ }^{1}$ and have worked to reduce this burden with a range of tobacco control initiatives. The ACCHS sector includes about 150 health services across Australia, each governed and managed by its local Aboriginal community, as well as representative state or territory organisations (Affiliates) and the National Aboriginal Community Controlled Health Organisation (NACCHO).
\end{abstract}

In 2001, NACCHO surveyed 67 staff from Aboriginal health services, 124 Aboriginal and Torres Strait Islander community members from 13 locations, and 76 health services with predominantly Aboriginal and Torres Strait Islander clients. ${ }^{2}$ The survey identified high levels of knowledge about the harmful health effects of tobacco, a lack of specific tobacco control programs and the need for more information on effective stopsmoking interventions. The report recommended that governments prioritise and fund tobacco control through policies that deal with social determinants of smoking, workforce training, comprehensive long-term programs to reduce smoking, and ongoing evaluation. For ACCHSs, the report recommended making tobacco control a specific priority and integrating it into health service programs.

Since 2001, specific tobacco control programs have been widely implemented in ACCHSs, informed by evidence from individual evaluations and randomised controlled trials of Aboriginal tobacco control interventions, ${ }^{3-5}$ and literature reviews. ${ }^{6-9}$ ACCHSs have also learnt from each other by sharing examples of what has (or has not) worked well..$^{10-12}$

In 2008, the federal government increased support through the $\$ 14.5$ million Indigenous Tobacco Control Initiative over 3 years, followed in

Abstract

Objectives: To describe tobacco control policies and activities at a nationally representative sample of Aboriginal community-controlled health services (ACCHSs).

Design, setting and participants: The Talking About The Smokes (TATS) project used a quota sampling design to recruit $34 \mathrm{ACCHSs}$ around Australia. Between April 2012 and October 2013, a representative at each ACCHS completed a survey about the service's tobacco control policies and activities. Questions about support for smoke-free policies were also included in the TATS project survey of 2435 Aboriginal and Torres Strait Islander members of the communities served by the ACCHSs.

Main outcome measures: ACCHS tobacco control policies and activities.

Results: Thirty-two surveys were completed, covering 34 sites. Most ACCHSs (24/32) prioritised tobacco control "a great deal" or "a fair amount", and all services had smoke-free workplace policies. Most had staff working on tobacco control and had provided tobacco control training within the past year. A range of quit-smoking information and activities had been provided for clients and the community, as well as extra smoking cessation support for staff. There was strong support for smoke-free ACCHSs from within the Aboriginal communities, with $87 \%$ of non-smokers, $85 \%$ of ex-smokers and $77 \%$ of daily smokers supporting a complete ban on smoking inside and around ACCHS buildings.

Conclusions: The high level of commitment and experience within ACCHSs provides a strong base to sustain further tobacco control measures to reduce the very high smoking prevalence in Aboriginal and Torres Strait Islander populations.

2009 by a $\$ 100.6$ million commitment over 4 years to the Council of Australian Governments' Tackling Indigenous Smoking measure. ${ }^{13,14}$ These funded social marketing, quit support and other programs, with the goal of halving smoking rates in Aboriginal and Torres Strait Islander communities by 2018. Forty ACCHSs and three NACCHO Affiliates received funds for tobacco control activities under these initiatives. Smoke-free workplace policies for ACCHSs and other organisations delivering Aboriginal primary health care were mandated in funding contracts with the Australian Government from July 2012. ${ }^{15}$

These tobacco control activities occurred in the wider Australian context of expanding smoke-free legislation, increases in tobacco taxation, plain packaging of cigarettes and ongoing social marketing campaigns.

The Talking About the Smokes (TATS) project, part of the International Tobacco Control Policy Evaluation
Project, aims to assess the impact of tobacco control policies on the Aboriginal and Torres Strait Islander population. Here, we describe the tobacco control policies, activities and programs reported by the ACCHSs participating in the TATS project.

\section{Methods}

The TATS project involved 35 communities served by 34 ACCHSs and one community in the Torres Strait where there is no ACCHS and health services are provided by Queensland Health. ACCHSs were selected to reflect the distribution of the Aboriginal and Torres Strait Islander population by state or territory and remoteness. The methods are described in detail elsewhere. ${ }^{16,17}$

Briefly, at 30 sites, we aimed to survey up to 50 smokers or ex-smokers who had quit $\leqslant 12$ months before and 25 non-smokers, with equal numbers of men and women and those aged $18-34$ years and $\geqslant 35$ years. In four large city sites and the Torres Strait 
1 Smoke-free policies at health services $(n=32)$

\section{Policy details}

Health services

Policy content

No smoking indoors

Designated outdoor smoking area

No smoking indoors or outdoors within the $\quad 28$

boundary/fence of health service

No smoking in work vehicles $\quad 32$

No smoking in health service uniform $\quad 18$

No smoking in work time

Other*

9

5

How the policy was communicated

Written policy 32

Signs 28

Staff meetings and/or newsletters $\quad 25$

How many staff and clients follow all elements of the policy

Almost all 17

Most 11

Some 3

Only a few

1

* Such as no staff smoking with clients or other staff, when offsite in an

official capacity or outside designated meal breaks.

community, the sample sizes were doubled. Between April 2012 and October 2013, trained local interviewers completed the 30-60 minute community surveys face to face using a computer tablet. The community sample closely matched the distribution of age, sex, jurisdiction, remoteness and number of cigarettes smoked per day reported in the 2008 National Aboriginal and Torres Strait Islander Social Survey. However, there were inconsistent differences in some socioeconomic indicators: our sample had higher proportions of unemployed people, but also higher proportions who had completed Year 12 and who lived in more advantaged areas. ${ }^{17}$

The TATS project also invited representatives at each site to complete a single policy monitoring survey, including questions about health service size and location; tobacco control funding, resources and policies; cessation support; and advocacy. The policy monitoring surveys were paper-based, designed to take less than 10 minutes, and were completed by staff members selected by the ACCHS. Policy monitoring surveys were completed while community surveys were being conducted at that site. Questions from the policy monitoring and community surveys analysed here are listed in Appendix 1.

The project was approved by three Aboriginal human research ethics committees (HRECs) and two HRECs with Aboriginal subcommittees: Aboriginal Health \& Medical Research Council Ethics Committee, Sydney; Aboriginal Health Research Ethics Committee, Adelaide; Central Australian HREC, Alice Springs; HREC for the Northern Territory Department of Health and Menzies School of Health Research, Darwin; and the Western Australian Aboriginal Health Ethics Committee, Perth.

\section{Statistical analyses}

We report the numbers of ACCHSs with different levels of tobacco control resourcing, activities and smoke-free policies; and the percentage and frequency of community members supporting smoking bans. Using the $\chi^{2}$ test, we assessed variation between services by size of service $(<50$ or $\geqslant 50$ staff); whether the service had received dedicated tobacco control funding in the past year; and its reported prioritisation of tobacco control in the past year ("not at all", "just a little", "a fair amount" or "a great deal").

At the first project site, the question about prioritisation of tobacco control was not asked, and two questions about dispensing and prescribing free nicotine replacement therapy were asked as a single question. Less than $0.5 \%$ of respondents to the community survey did not answer the questions about smoking bans. These missing values were excluded from our analyses. We also excluded results from the Torres Strait community without an ACCHS.

\section{Results}

The 32 completed policy monitoring surveys describe tobacco control activities at 34 sites, as a single survey was completed by the umbrella ACCHS for three participating sites in one area. Nineteen services had 50 or more staff and 13 had fewer than 50 .

\section{Tobacco control resourcing and activities at ACCHSs}

Nineteen of 32 ACCHSs reported receiving specific funding for tobacco control programs in the past 12 months. Another three used untied funds for tobacco control programs. Dedicated tobacco control funding was not associated with the size of the ACCHS $(P=0.84)$ or its reported prioritisation of tobacco control $(P=0.19)$. Thirteen ACCHSs reported prioritising tobacco control a great deal, 11 a fair amount and seven just a little. Eighteen ACCHSs had a staff position with a major focus on tobacco control.

Staff of 27 services had attended tobacco control training in the past year. There was no association between staff attending training and the size of the service $(P=0.31)$ or dedicated tobacco control funding $(P=0.34)$. However, there was an association with the prioritisation of tobacco control $(P=0.04)$, with some staff attending training at all 13 ACCHSs that had prioritised it a great deal. The training had been provided by a range of organisations, including NACCHO Affiliates, the Centre for Excellence in Indigenous Tobacco Control, cancer councils, quit organisations and state health departments.

\section{Aboriginal and Torres Strait Islander community support for smoke-free environments $(n=2435) *$}

\begin{tabular}{|c|c|c|c|c|}
\hline Smoking ban & $\begin{array}{l}\text { Daily smokers } \\
\quad(n=1342)\end{array}$ & $\begin{array}{l}\text { Non-daily smokers } \\
\quad(n=233)\end{array}$ & $\begin{array}{c}\text { Ex-smokers } \\
(n=299)\end{array}$ & $\begin{array}{c}\text { Never-smokers } \\
(n=561)\end{array}$ \\
\hline Smoking should be banned everywhere at ACCHSs & $77 \%(1030)$ & $85 \%(197)$ & $85 \%(255)$ & $87 \%(487)$ \\
\hline Smoking should be banned indoors at other Aboriginal organisations & $93 \%(1242)$ & $93 \%(217)$ & $95 \%(284)$ & $97 \%(544)$ \\
\hline Smoking should be banned at outdoor festivals and sporting events & $51 \%(687)$ & $70 \%(163)$ & $65 \%(194)$ & $71 \%(398)$ \\
\hline
\end{tabular}

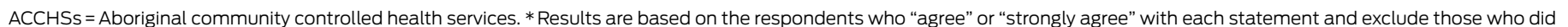
not answer. 
In the past 12 months, 17 of 32 services had run programs to help people quit smoking. These included Aboriginalspecific tobacco control and healthy lifestyle programs, as well as mainstream quit programs. In all but one of these services, Aboriginal health workers or tobacco action workers were involved in running the program. Programs had been evaluated in nine services, some with internal surveys and others with the assistance of NACCHO Affiliates or universities.

Free nicotine replacement therapy was prescribed or dispensed by 25 of the 32 services. Most ACCHSs (21/34) supported staff who smoked by providing them with extra smoking cessation support, either by facilitating access to programs available to clients or through specific programs for staff.

\section{Smoke-free workplace policies}

All ACCHSs reported having a formal smoke-free policy in place. The features of these policies and the reported levels of adherence are described in Box 1 . In contrast, only 18 of 32 services reported that most or all other Aboriginal and Torres Strait Islander organisations in their community were smoke-free; 10 reported that some were smoke-free and four that none were.

Community survey respondents $(n=2435)$ reported a high level of support for smoking bans everywhere at ACCHSs and indoors at other Aboriginal organisations, with less (but still majority) support for bans at outdoor community events (Box 2). Among the daily smokers who did not support total bans at ACCHSs, $82 \%(251 / 306)$ supported indoor bans. Daily smokers were least likely to support any of the bans.

\section{Health promotion}

All 32 ACCHSs provided locally or externally produced quit-smoking information to their communities, most commonly using posters, pamphlets and displays at information days or other community events, but also using newer media such as the internet and social media (Box 3). Health services with dedicated tobacco control funding were more likely to use locally developed posters $(P=0.03)$ and pamphlets $(P=0.02)$ in the clinic, and to give pamphlets to other organisations $(P=0.02)$, but there were no significant associations with funding when these locally developed items were considered together with externally developed information, or for other types of information. Ten services reported smoking or quitting stories featuring someone from their health service in mainstream or Aboriginal and Torres Strait Islander television, radio or newspaper news.

Nineteen ACCHSs reported discussing tobacco control policy at meetings with government and non-government organisations in the previous year, with 11 reporting that they had influenced local, regional or national tobacco control policy.

\section{Discussion}

We found that tobacco control initiatives are a priority in ACCHSs, with all reporting smoke-free workplace policies to reduce smoking and exposure to second-hand smoke. Staff with specific tobacco control training are providing a range of evidence-informed quit-smoking programs in health services and in the wider Aboriginal and Torres Strait Islander community. This increased tobacco control activity was not just found in health services with dedicated Aboriginal and Torres Strait Islander tobacco control funding.

Elsewhere in this supplement, we show that more community members from sites with dedicated tobacco control resources had been advised to quit, ${ }^{18}$ recalled noticing cigarette pack warning labels, ${ }^{19}$ made quit attempts ${ }^{20}$ and used stop-smoking medicines ${ }^{21}$ than those from sites without dedicated resources. However, there were no such significant differences for wanting to quit, ${ }^{22}$ smoke-free homes, ${ }^{23}$ recalling advertising and news stories about smoking and quitting, ${ }_{1}^{19}$ and personal attitudes towards smoking. ${ }^{24}$

A limitation to our study is that although the selected ACCHSs are geographically representative of the Aboriginal and Torres Strait Islander population, the ACCHSs that responded to the call for participation are likely to be biased towards those that were more interested and active in tobacco control. Further, the people
3 Health services using different media to disseminate quit-smoking information $(n=32)$

Quit-smoking information

Health services

Posters in clinic

31

Pamphlets in clinic

29

Health information days and events 28

Displays at other community events 26

Posters in other community locations

Pamphlets given to other organisations 23

Newsletters

21

Website

Social media

Newspaper or community magazine

Local radio advertisement

CD/DVD

Local television advertisement

Mobile phone messages

18

14

12

11

11

11

2

2

completing the policy survey may have been unaware of all services and policies or may have overstated what was being provided. It was difficult to categorise services by their level of tobacco control activity because of the differences in the range of activities offered. Consequently, it was not possible to detect a relationship between dedicated funding and level of tobacco control activity. Furthermore, the small number of health services in our study did not allow identification of enablers and barriers to services prioritising tobacco control work, a useful area to explore in future research.

Our findings on smoke-free policies are not surprising, given implementing smoke-free work environments became a condition of funding for ACCHSs at the same time this study was conducted. ${ }^{15}$ However, it is likely that some aspects of these policies predated the funding requirement, given that all 76 Aboriginal health services surveyed in 2001 reported indoor smoking bans, with the policies of $32 \%$ of services including broader measures. ${ }^{2}$ Our results provide evidence that many ACCHSs have more comprehensive policies, such as banning staff from smoking with clients and other staff or where they can be seen or while in uniform, and the provision of cessation support for staff. The incremental approach of ACCHSs in developing and strengthening policy content and implementation has common ground with government approaches to tobacco control, where 
success with indoor smoking bans was followed by an emphasis on initial exceptions, such as pubs and prisons, and on outdoor areas such as outdoor dining areas and street malls. ${ }^{25}$

The high level of community support for smoking bans that we found may reflect the wider tobacco control environment and the active involvement of ACCHS managers, staff and the community in tobacco control over the preceding decade. ACCHSs reported that policies relating to smoking behaviour of Aboriginal staff and the community have evolved over time, as the measures have been contested and negotiated in various Aboriginal community forums. This has included discussions about the right to smoke and the right to be protected from secondhand smoke, the social inclusion of sharing cigarettes and the significance of denormalising smoking and modelling healthier behaviour to children. ${ }^{11,26}$

The relatively small size of many ACCHSs provides an environment to test out policy measures that can then be either discarded as unacceptable or ineffective, or promoted as successful measures to other Aboriginal, community and health organisations. A key characteristic of ACCHSs is that a community with a high prevalence of smoking is involved in making and implementing decisions in areas they can control, such as workplaces and community events, thus providing Aboriginal leadership and contributing to shifts in social norms in their community. Aboriginal health services are well placed to influence social norms because of the large number of Aboriginal and Torres Strait Islander people who work there and use their services - 3618 full-time equivalent staff and 314000 clients in 2012-13. ${ }^{27}$ There is an opportunity for ACCHSs to influence other Aboriginal and Torres Strait Islander organisations in their communities that do not have smoke-free policies.

It would be useful to monitor the diffusion of the successful and innovative tobacco control work both within and beyond the ACCHS sector, and to look to ACCHSs for new ideas in the future. The high level of commitment and experience in ACCHSs provides a strong base for sustainable interest and activity to further reduce smoking levels and smokingrelated harm.

Acknowledgements: The full list of acknowledgements is available in Appendix 2.

Competing interests: No relevant disclosures.

Provenance: Not commissioned; externally peer reviewed.
Received 18 Feb 2015, accepted 6 May 2015.

1 National Aboriginal Health Strategy Working Party. National Aboriginal Health Strategy. Canberra: AGPS, 1989.

2 Lindorff KJ. Tobacco: time for action. National Aboriginal and Torres Strait Islander Tobacco Control Project. Final report. Canberra: National Aboriginal Community Controlled Health Organisation, 2002.

3 Eades SJ, Sanson-Fisher RW, Wenitong M, et al. An intensive smoking intervention for pregnant Aboriginal and Torres Strait Islander women: a randomised controlled trial. Med J Aust 2012; 197: 42-46.

4 Marley JV, Kitaura T, Atkinson D, et al. Clinical trials in a remote Aboriginal setting: lessons from the BOABS smoking cessation study. BMC Public Health 2014; 14: 579.

5 Walker $\mathrm{N}$, Johnston V, Glover M, et al. Effect of a family-centered, secondhand smoke intervention to reduce respiratory Illness in indigenous infants in Australia and New Zealand: a randomized controlled trial. Nicotine Tob Res 2015; 17: 48-57.

6 Briggs VL, Lindorff KJ, Ivers RG. Aboriginal and Torres Strait Islander Australians and Tobacco. Tob Control 2003; 12 Suppl 2: ii5-ii8.

7 Ivers RG. An evidence-based approach to planning tobacco interventions for Aboriginal people. Drug Alcohol Rev 2004; 23: 5-9.

8 Power J, Grealy C, Rintoul D. Tobacco interventions for Indigenous Australians: a review of current evidence. Health Promot J Austr 2009; 20: 186-194.

9 Winstanley M (updated by van der Sterren A, Knoche D). Tobacco use among Aboriginal peoples and Torres Strait Islanders. In: Scollo MM, Winstanley MH, editors. Tobacco in Australia: facts and issues. 4th ed. Melbourne: Cancer Council Victoria, 2012. http://www.tobaccoinaustralia.org. au/chapter-8-aptsi (accessed Mar 2015).

10 Centre for Excellence in Indigenous Tobacco Control. Marrining Moorup (Improve Life): Oceania Tobacco Control 2011 Indigenous pre-conference workshop report. Melbourne: CEITC, 2012.

1 Queensland Aboriginal and Islander Health Council. Aboriginal and Torres Strait Islander tobacco control. Queensland Aboriginal and Islander community controlled health services: creating supportive workplace environments. Brisbane: QAIHC, 2009. http://www.qaihc.com. au/wp-content/plugins/download-monitor/ download.php?id=QAIHC-Sector-Smoking-Policy. pdf (accessed Mar 2015).

12 Russ P, van der Sterren A. Indigenous tobacco control in Australia: everybody's business. National Indigenous Tobacco Control Research Roundtable report: Brisbane, Australia 23 May 2008. Melbourne: Centre for Excellence in Indigenous Tobacco Control, 2008.

13 Council of Australian Governments. National Indigenous Reform Agreement (Closing the Gap). Canberra: COAG, 2008.

14 Council of Australian Governments. National Partnership Agreement on closing the gap in
Indigenous health outcomes. Canberra: COAG, 2009.

15 Office for Aboriginal and Torres Strait Islander Health. Funding agreement book, version 2. Canberra: Department of Health and Ageing, 2012.

16 Couzos S, Nicholson AK, Hunt JM, et al. Talking About The Smokes: a large-scale, communitybased participatory research project. Med J Aust 2015; 202 (10 Suppl): S13-S19.

17 Thomas DP, Briggs VL, Couzos S, et al. Research methods of Talking About The Smokes: an International Tobacco Control Policy Evaluation Project study with Aboriginal and Torres Strait Islander Australians. Med J Aust 2015; 202 (10 Suppl): S5-S12.

18 Thomas DP, Bennett PT, Briggs VL, et al. Smoking cessation advice and non-pharmacological support in a national sample of Aboriginal and Torres Strait Islander smokers and ex-smokers. Med J Aust 2015; 202 (10 Suppl): S73-S77.

19 Nicholson AK, Borland R, Sarin J, et al. Recall of anti-tobacco advertising and information, warning labels and news stories in a national sample of Aboriginal and Torres Strait Islander smokers. Med J Aust 2015; 202 (10 Suppl): S67-S72.

20 Nicholson AK, Borland R, Davey ME, et al. Past quit attempts in a national sample of Aboriginal and Torres Strait Islander smokers. Med J Aust 2015; 202 (10 Suppl): S20-S25.

21 Thomas DP, Briggs VL, Couzos S, et al. Use of nicotine replacement therapy and stop-smoking medicines in a national sample of Aboriginal and Torres Strait Islander smokers and ex-smokers. Med J Aust 2015; 202 (10 Suppl): S78-S84.

22 Nicholson AK, Borland R, Davey ME, et al. Predictors of wanting to quit in a national sample of Aboriginal and Torres Strait Islander smokers. Med J Aust 2015; 202 (10 Suppl): S26-S32.

23 Thomas DP, Panaretto KS, Stevens M, et al. Smoke-free homes and workplaces of a national sample of Aboriginal and Torres Strait Islander people. Med J Aust 2015; 202 (10 Suppl): S33-S38.

24 Nicholson AK, Borland R, Bennet PT, et al. Personal attitudes towards smoking in a national sample of Aboriginal and Torres Strait Islander smokers and recent quitters. Med J Aust 2015; 202 (10 Suppl): S51-S56.

25 Scollo M. Trends in tobacco consumption. In: Scollo M, Winstanley MH, editors. Tobacco in Australia: facts and issues. 4th ed. Melbourne: Cancer Council Victoria, 2012. http://www. tobaccoinaustralia.org.au/chapter-2-consumption (accessed Mar 2015).

26 Tasmanian Aboriginal State Health Forum. Priority action area: reducing tobacco related harm among Tasmanian Aborigines. Statement of intention. Hobart: Tasmanian Aboriginal State Health Forum, 2005.

27 Australian Institute of Health and Welfare. Aboriginal and Torres Strait Islander health organisations: online services report - key results 2012-13. Canberra: AlHW, 2014. 